\title{
Alligator eyes: beware the occipital dermoid
}

\author{
Jignesh K. Tailor $^{1} \cdot$ Aylin Tekes $^{2} \cdot$ Melike Guryildirim $^{2} \cdot$ Alan R. Cohen ${ }^{1}$ (I) \\ Received: 6 December 2020 / Accepted: 9 December 2020 / Published online: 3 January 2021 \\ (C) The Author(s), under exclusive licence to Springer-Verlag GmbH, DE part of Springer Nature 2021
}

Keywords Dermal sinus · Dermoid cyst $\cdot$ Posterior fossa $\cdot$ CT $\cdot$ MRI $\cdot$ Alligator

"How the seen looks depends on how the seer sees." Mokokoma Mohkhonoama

Philosopher and social critic, Limpopo, South Africa November 2020

A 7-year-old boy was admitted to the Johns Hopkins Hospital with 3 days of headache, vomiting, and fever. He had a similar spell 2 years ago that resolved spontaneously. On examination, he was lethargic and in moderate distress. A small punctum was noted in the midline occipital scalp just rostral to the inion. His mother commented that the punctum had been present since birth.

Cranial CT at an outside hospital showed a small midline extracranial subcutaneous nodule connected by a sinus tract to a large round heterogeneous intradural mass in the midline posterior fossa. There was non-communicating hydrocephalus. The intradural mass scalloped the occipital bone. Findings were confirmed on MRI (Fig. 1a) and suggested a dermal sinus and intradural dermoid.

The dermal sinus and dermoid were removed through a posterior fossa craniotomy (Fig. 1b).

Scalloping created by the dermoid displaced the normal median internal occipital keel and created two crests, one on either side of the midline depression in the skull (Fig. 2, left panel). These two crests and the depression between them closely resembled the appearance of an alligator lurking in the water with its predatory eyes just above the surface (Fig. 2, right panel). The authors introduce the descriptor, Alligator Eyes, as a radiographic sign of an occipital dermoid or other congenital mass lurking in the posterior fossa midline. This menacing alligator was captured on film in 2009 by nature photographer Larry Lynch, kneeling nearby in the black mud of the Myakka River in St. Petersburg, Florida, just after sunset.

Alan R. Cohen

alan.cohen@jhmi.edu

1 Department of Neurosurgery, Division of Pediatric Neurosurgery, The Johns Hopkins University School of Medicine, 600 North Wolfe Street, Phipps 556, Baltimore, MD 21287, USA

2 Department of Radiology, Division of Pediatric Neuroradiology, The Johns Hopkins University School of Medicine, Baltimore, MD, USA 


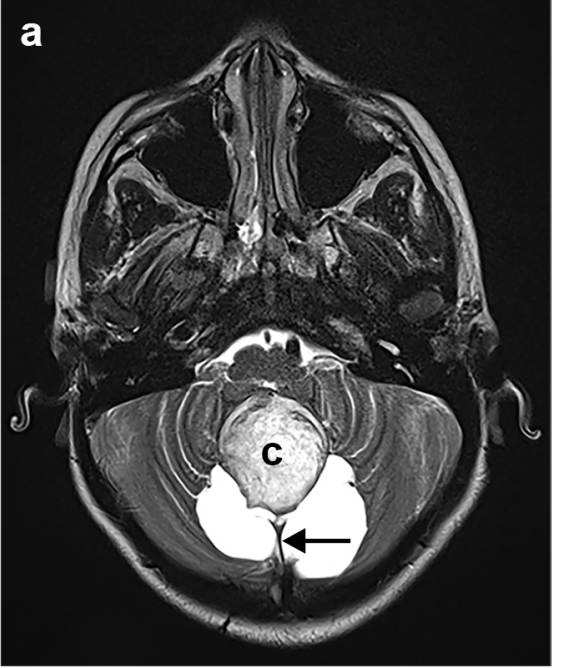

Fig. 1 a Preoperative T2 axial MRI showing the dermoid cyst (c) as a round heterogeneous mass centered in the inferior cerebellar vermis compressing the brainstem. The dermoid is surrounded by a T2-bright arachnoid cyst. A midline dermal sinus (arrow) connects the intradural dermoid cyst to a small extracranial subcutaneous nodule. On other imaging sequences, the dermoid cyst strongly restricts diffusion and shows weak peripheral enhancement. b Operative photograph (rostral is to the

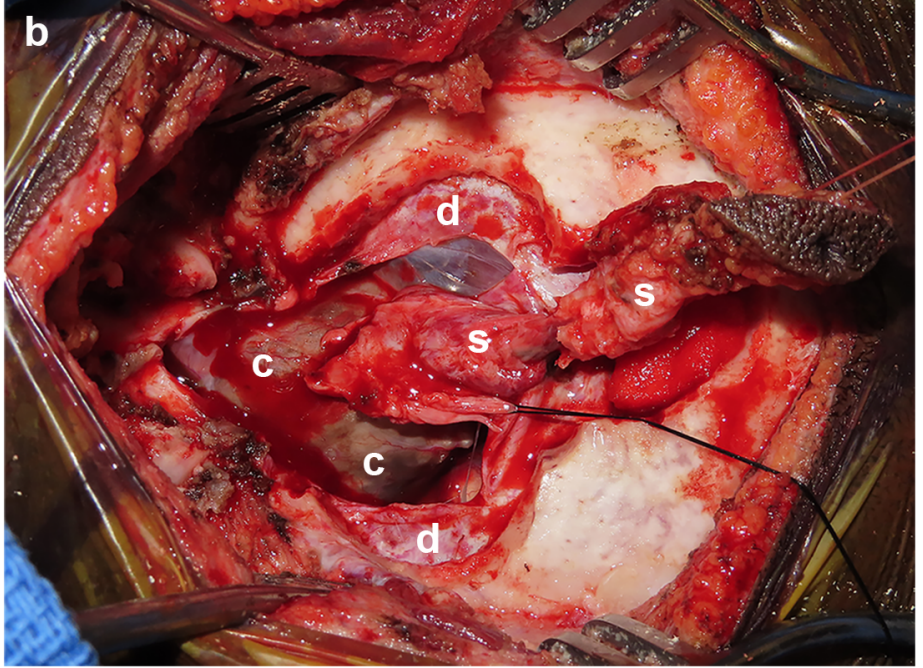

right). Posterior fossa craniotomy. A small punctum in the scalp on the right caps a dermal sinus tract (s) that courses through the subcutaneous tissue and skull to connect with a large intradural dermoid cyst (c) which has scalloped the overlying bone at the inferior aspect of the posterior fossa. The dura (d) has been opened and the posterior arch of $\mathrm{C} 1$ has been removed to facilitate excision of the cyst, which was densely adherent to the cerebellum and brainstem, likely from prior rupture
Fig. 2 and Cover left panel Preoperative CT (bone window) showing scalloping of the midline occipital bone by the dermoid cyst with displacement of the normal medial occipital crest and the creation of two separate crests, one on either side of the midline (outlined by blue rectangle). right panel Alligator eyes sign. Frightening glare of the glowing red eyes of a predatory alligator lurking below the surface of the Myakka River, photographed by Larry Lynch. Published with permission

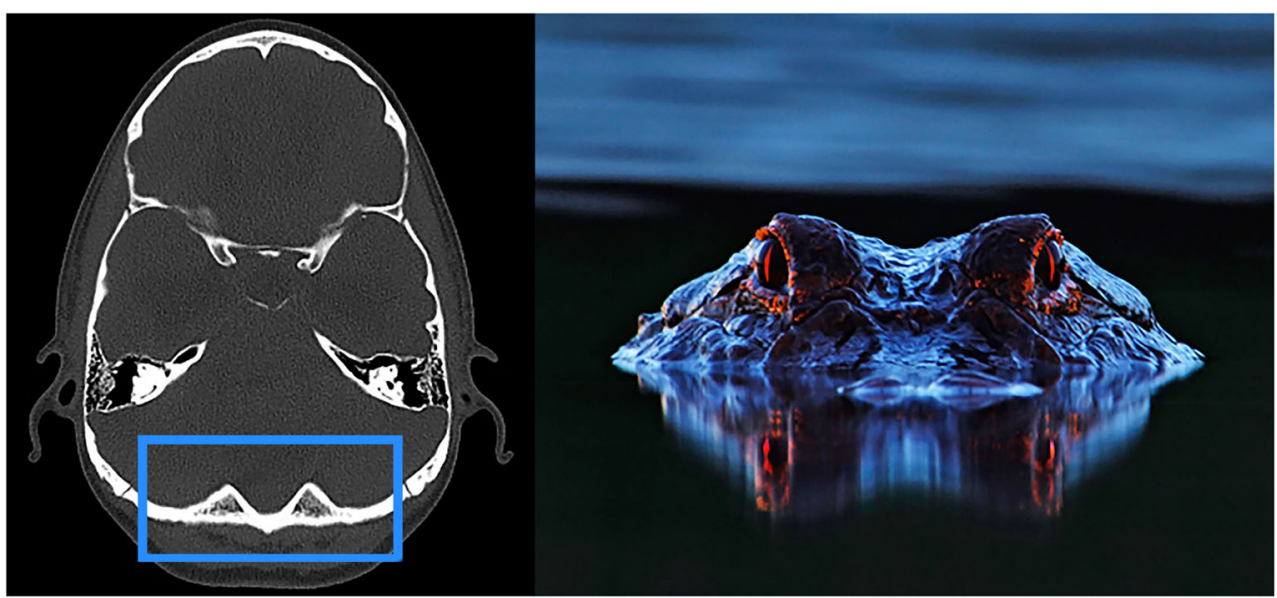

Acknowledgments The authors are grateful to nature photographer Larry Lynch, St. Petersburg, Florida for use of his extraordinary photograph entitled, Alligator Eyeshine \#2 (Fig. 2b).

Data availability All data are available.

\section{Compliance with ethical standards}

Conflicts of interest The authors declare that they have no conflict of interest.
Ethics approval Not applicable.

Consent to participate Not applicable.

\section{Consent for publication Obtained.}

Code availability Not applicable.

Publisher's note Springer Nature remains neutral with regard to jurisdictional claims in published maps and institutional affiliations. 